\title{
Obesity and Optimal Breastfeeding Practices in Developing Countries: A Double Staged Study
}

\section{Azza Abul-Fadl ${ }^{1^{*}}$ and Shewikar El Bakry ${ }^{2}$}

${ }^{1}$ Department of Pediatrics, Benha Faculty of Medicine, Benha University, Egypt

${ }^{2}$ Department of Psychiatry, Benha Faculty of Medicine, Benha University, Egypt

*Corresponding author: Fadl AA, Department of Pediatrics, Faculty of Medicine, Benha University, Egypt, Tel: 0133225491; Email: azza_abulfadl@yahoo.com

Received date: 04 April 2018; Accepted date: 13 April 2018; Published date: 20 April 2018

Copyright: ( 2018 Abul-Fadl A, et al. This is an open-access article distributed under the terms of the Creative Commons Attribution License, which permits unrestricted use, distribution, and reproduction in any medium, provided the original author and source are credited.

\begin{abstract}
Background: Developing countries suffer escalating rates of overweight and obesity; increasing the burden of diseases attributable to obesity. Optimal breastfeeding is linked with prevention of obesity.

Aim: To identify the optimal breastfeeding practices that can reduce the burden of overweight and obesity with a focus on countries of the Eastern Mediterranean region (EMR).

Methods: This was a combined assessment double staged study. In the first stage WHO and UNICEF data base from household surveys for the 22 countries of the EMR for breastfeeding rates of timely first suckle (TFS), EBF, continued breastfeeding at 12 and 24 months and correlated and with data for overweight and obesity in children under five (CU5), youth and adults. In the second stage we conducted a retrospective cross-sectional field survey in one country (Egypt) for 120 preschool children, 60 were breastfed and 60 were artificially fed. The groups were compared for weight, length and midarm circumference using the WHO growth standards.
\end{abstract}

Results: Obesity in the EMR countries is high and is on the rise. Breastfeeding practices mainly TFS and continued breastfeeding for 24 months are suboptimal in the EMR countries irrespective of their socioeconomic status. There were significant negative correlations between TFS and obesity among CU5 ( $r-0.51)$ and obesity in adults $(r-0.37)$. Continued breastfeeding for 12 and 24 months were also significantly correlated with obesity in CU5 ( $r-0.475$ and $r-0.33$ respectively) and obesity in adults ( $r-0.49$ and $r-0.52$ respectively). This was confirmed by the field study that was done for the children under five of age that showed a significant difference in weight centiles between the breastfed and non-breastfed children at $\mathrm{P}<0.05$.

Conclusions: Early feeding practices are suboptimal in EMR countries and influence the high rates of obesity and overweight in the countries of the region. Focus on improving timely initiation of breastfeeding in the first hour and prolonging the duration of breastfeeding to two years may contribute significantly in the reduction of the burden of overweight and obesity in the region.

Keywords: Obesity; Overweight; Exclusive breastfeeding; Breastfeeding duration; Breastfeeding patterns; Eastern Mediterranean region

\section{Background}

Exclusive breastfeeding (EBF) for the first six months and continued breastfeeding for two years are the optimal breastfeeding practices that are recommended by the World Health Organization and UNICEF [1]. The evidence supporting optimal breastfeeding practices and their importance in preventing deaths from poor nutritional status, communicable and noncommunicable disease (NCD) has been shown several workers [2-4]. In addition, evidence shows that breastfeeding promotion is the most effective intervention to prevent deaths worldwide [4].

Obesity and overweight are growing problems worldwide [5] and especially in the EMR [6] were countries are exposed to the double risk of both under and overnutrition. Several workers have shown that rapid weight gain in early infancy is linked with obesity [7]. On the other hand, EBF practices when measured at 4 to 5 months were found to be closely linked with reduction of obesity $[8,9]$. Unfortunately, breastfeeding practices in the Arab countries have been shown to be far from optimal [10]. Many mothers will opt breastfeeding as they approach one year or beyond. Although research is building up to the importance of continued breastfeeding for two years, yet evidence is not sufficient to link it to serious disease and handicapping states. Research has shown that breastfeeding continuity is particularly beneficial to mothers as it prevents many serious chronic diseases as breast and ovarian cancer [3].

Studies that rely on global data can give a global perspective to the problem. However, when combined with case studies and field surveys they can bring more light to the magnitude of the problem. Also, indicators of early feeding patterns rely on soft data, for instance in demographic surveys exclusive breastfeeding rate measures only what the baby has consumed over the past 24 hours. Such measures do not take into consideration whether the baby was really exclusively breastfeeding over the past 6 months. The pathogenesis of the influence of how early feeding practices influence the predisposition to obesity is not fully understood. Many hypotheses were put forward 
including hormonal influences that may be altered, or storage capacities of the fat cells or aspects related to satiety and control of appetite, or even the body metabolic performance which is determined early in life may be influenced by type or mode of feeding as in the case of exposure to high protein diet [4]. Breastfeeding is not about just taking breastmilk only, but more about how we feed the baby i.e., whether it is responsive feeding or scheduled or limited or even limited by day or night feeds. Hence the complexity of intervening factors that can intervene make it difficult to define how we can define the most appropriate early feeding practice that can protect against future obesity. We hypothize in this article that it is the continuation of breastfeeding during these early vulnerable years of the life of a child that can ultimately influence how his or her body can prevent the ill consequences of overweight and obesity.

The aim of this work is to identify the optimal of breastfeeding practices that can directly influence the nutritional status particularly the increased risk to obesity and overweight in the region. Also, we aim at identifying appropriate strategies related to early feeding practices that can be adopted by countries in policy and planning to overcome the pandemic of overweight in the region.

\section{Materials and Methods}

This was a combined assessment double staged study. In the first stage WHO and UNICEF data base from household surveys for the 22 countries of the EMR for breastfeeding rates of timely first suckle (TFS), EBF, continued breastfeeding at 12 and 24 months and correlated and with data for overweight and obesity in children under five (CU5), youth and adults. In the second stage we conducted a retrospective cross-sectional field survey for 120 preschool children, 60 were breastfed and 60 were artificially fed.

\section{Data source and collection}

Data was retrieved from the World Health Organization (WHO), Eastern Mediterranean Region (EMR) Framework for health information systems and core indicators for monitoring health situation and health system performance for 2015 and 2017 for the 22 countries of the EMR region. Missing data was completed from the UNICEF Multicenter Indicator Cluster Surveys (MICS) of UNICEF accessed on mics.unicef.org. The results from the most recent MICS surveys, carried out in from 1995, are becoming progressively available online and are updated for countries every 3 to 5 years. The nutritional status for the 22 countries of the EMR were analyzed and correlated to breastfeeding rates for timely first suckle (TFS), EBF, continued breastfeeding for 12 and 24 months in children under five years of age (CU5), youth and adults. Data for overweight and obesity for children under five and adults were retrieved from the same data banks. The data represented surveys that were conducted over the past 10 to 15 years from 2000 to 2015. Timely first suckle was defined as early initiation of breastfeeding within the first hour immediately after birth. EBF was measured from data bases and represented the pattern of feeding only on mother's milk from birth up to 5 months of age (0-5 months) with no introduction of bottles, pacifiers, drinks or other milks or even water (except for medicine or vitamin drops). Continued breastfeeding for 12 and 24 months was defined as mothers who were still breastfeeding whether or not child was receiving other adequate foods or bottles or pacifiers and irrespective of frequency or duration of breastfeeding.
Countries were further classified by socioeconomic status into low, middle and high-income countries as per income status below poverty line and statistically analyzed.

High Income countries (LIC) included 6 countries: Bahrain, Kuwait, Qatar, Saudi Arabia, Oman and United Arab Emirates with a per capita GDP (10350).

Middle Income countries (MIC) included 11 countries: Egypt, Jordon, Iran, Iraq, Lebanon, Libya, Morocco, Pakistan, Palestine, Syrian Republic and Tunisia. Poverty line is within $25 \%$ or less i.e., percentage of populations living in poverty are around 25\% with per capita GDP (1464-2655).

Low Income countries (LIC) included 5 countries: Afghanistan, Djibouti, Somalia, Sudan and Yemen. These have poverty line above $35 \%$ i.e., percentage of populations living in poverty are above $35 \%$ with per capita GDP (430).

\section{Retrospective field survey}

To validate the above data, we carried out a retrospective crosssectional analysis in one country. The country selected was Egypt as it has a high population density for the region and for convenience as investigators were from the same country. It was carried out in semiurban region of the country 60 kilometers from the city of Cairo. The data was collected from children attending a preschool nursery. Their ages ranged between 3-5 years. The sample was selected randomly using random numbers for every other child over a defined period. They included two groups: children who were breasted well into the second year (60) and children who had never been breastfed (60). All children were assessed by anthropometry for weight (to the nearest gram) and height (to the nearest $\mathrm{cm}$ ) using standardized methods for anthropometric assessment and standardized scales. The measurements were interpreted using the standard WHO growth standards for children under-five years of age.

The work of the paper was in compliance with the ethical principles of Helsinki Declaration (1964). The protocol of the study was conducted in collaboration with the EM regional office of the World Health Organization, nutrition unit.

\section{Statistical Analysis}

The collected data were organized, tabulated and statistically analyzed using SPSS version 20(SPSS Inc; Chicago, Illinois), running on IBM compatible computer with Microsoft Windows 7 Operating System. The qualitative data for the rates of breastfeeding and nutritional indices were presented as discrete data per country and presented in mean and standard deviation for the region. We did not do statistical analysis for the income groups as the data for the number of countries were too small. Student t-test (for parametric data) and Mann-Whitney $U$ test (for non-parametric data) were used for comparison of 2 distinct groups. Whereas for the comparison of between the two study groups of breastfed versus artificially fed analysis of variance with post hoc Bonferroni test (for parametric data) and Kruskal-Wallis test followed by Mann-Whitney U test (for nonparametric data) were used. Categorical variables were compared using Chi square and Fisher exact tests. Spearman rank correlation coefficient was used to measure the strength and direction of linear relationship between two variables. The level of significance used as a cut off was $\mathrm{P}<0.05$. 
Citation: Abul-Fadl A, El Bakry S (2018) Obesity and Optimal Breastfeeding Practices in Developing Countries: A Double Staged Study. Vitam Miner 7: 177.

Page 3 of 7

\section{Results}

\section{Analysis of the regional data}

The mean TFS for 17 countries in the EMR was $48.5 \pm 24.25$, EBF $0-5$ months for the 22 countries was $34.03 \pm 18.88$, breastfeeding continuity for 12 months for 17 countries was $62.5 \pm 20.05$ and continuity rates for 24 months for 17 countries was $28.9 \pm 14.69$ (Table 1).

\begin{tabular}{|c|c|c|c|c|c|c|c|c|c|c|}
\hline & \multirow{2}{*}{$\begin{array}{l}\text { Timely } \\
\text { initiation of } \\
\text { BF (17) }\end{array}$} & \multirow{2}{*}{$\begin{array}{l}\begin{array}{l}\text { Exclusively } \\
\text { Breastfed (22) }\end{array} \\
0-5 \text { months }\end{array}$} & \multicolumn{2}{|c|}{$\begin{array}{l}\text { Continued } \\
\text { Breastfeeding (17) }\end{array}$} & \multicolumn{4}{|c|}{ Under five (21) } & \multicolumn{2}{|c|}{ Adults (22) } \\
\hline & & & 12 months & 24 months & Stunting & Wasting & $\begin{array}{l}\text { Over- } \\
\text { weight }\end{array}$ & $\begin{array}{l}\text { Obesity } \\
(15)\end{array}$ & $\begin{array}{l}\text { Over } \\
\text { weight }\end{array}$ & Obesity \\
\hline Afghanistan & 69 & 58.4 & 91.5 & 54.2 & 40.9 & 9.5 & 5.4 & 2 & 16.2 & 2.9 \\
\hline Bahrain & NA & 33.8 & NA & NA & 2.4 & 2.1 & 9.8 & 5.2 & 71.7 & 35.1 \\
\hline Djibouti & NA & 1.3 & 53.5 & 18.3 & 29.7 & 17.8 & 8.1 & NA & 31.9 & 9.6 \\
\hline Egypt & 27.1 & 39.7 & 80 & 20 & 22.3 & 9.5 & 15.7 & 8.5 & 62 & 28.9 \\
\hline Iran & 68.7 & 53.1 & 84 & 51 & 6.8 & 3 & 11.8 & 1.9 & 62.3 & 26.1 \\
\hline Iraq & 42.8 & 38 & 51.5 & 22.7 & 22.6 & 7.4 & 11.8 & 6 & 57.9 & 23.8 \\
\hline Jordon & 19 & 23 & 64 & 16 & 7.7 & 2.4 & 4.4 & NA & 65.9 & 30.5 \\
\hline Kuwait & 40 & 11.9 & 10.3 & 4.48 & 4.9 & 3.1 & 6 & 2.1 & 75.4 & 39.7 \\
\hline Lebanon & 17 & 14.8 & NA & NA & 7.3 & 6.6 & 16.7 & 6.3 & 68.7 & 31.9 \\
\hline Libya & NA & 67 & NA & NA & 21 & 6.5 & 22 & 10.5 & 68.7 & 33.1 \\
\hline Morocco & 30 & 27.8 & 66.5 & 24.9 & 14.9 & 3 & 10.7 & 2.4 & 56.5 & 22.3 \\
\hline Oman & NA & 14.4 & 72.2 & 48.4 & 9.8 & 7.5 & 1.7 & 0.5 & 67.4 & 30.9 \\
\hline Pakistan & 40 & 38 & 77.3 & 56 & 45 & 11 & 6.4 & 2.8 & 23 & 5.4 \\
\hline Palestine & 96.6 & 38.6 & 52.9 & 11.5 & 7.4 & 1.2 & 8.2 & NA & 53.8 & 26.8 \\
\hline Qatar & 34 & 29.3 & NA & 24.1 & 11.6 & 10.1 & 12.9 & 14 & 78.1 & 42.3 \\
\hline Saudi & 92 & 68.7 & NA & NA & 9.3 & 11.8 & 1.5 & NA & 69.6 & 34.7 \\
\hline Somalia & NA & 12.8 & 46.3 & 19.2 & 42.1 & 13.2 & NA & NA & 20.7 & 4.6 \\
\hline Sudan & 68.7 & 41 & 89.4 & 63.1 & 38.2 & 33 & 3 & NA & 27.8 & 7.5 \\
\hline Syria & 36.1 & 42.6 & 58.8 & 25.3 & 22.3 & 7.2 & 17.9 & 7.2 & 58.5 & 23.5 \\
\hline Tunisia & 39.9 & 8.5 & 49.2 & 19.1 & 10.1 & 2.8 & 14.3 & 2.3 & 62.9 & 27.1 \\
\hline UAE & 75 & 34 & 46.6 & 13 & NA & NA & NA & NA & 74 & 37.2 \\
\hline Yemen & 53 & 11.5 & 69 & NA & 47 & 16.3 & 2 & 0.4 & 46.8 & 17.2 \\
\hline Range & $96.9-17$ & $5.3-68.7$ & $10.3-80$ & $4.48-63.1$ & $2.4-47$ & $1.2-17.8$ & $1.7-17.9$ & $0.4-7.2$ & $20.7-75.4$ & $5.4-39.7$ \\
\hline Mean & 48.5 & 34.03 & 62.5 & 28.9 & 20.16 & 8.8 & 9.5 & 4.8 & 55.4 & 24.6 \\
\hline SDs & 24.25 & 18.88 & 20.05 & 18.09 & 14.69 & 7.3 & 5.87 & 3.94 & 19.13 & 11.88 \\
\hline
\end{tabular}

Table 1: Comparison indicators for breastfeeding and nutritional status in the countries of the Eastern Mediterranean region (EMR).

EBF was lowest in the LIC $(25 \pm 23.79)$ and continued breastfeeding for 12 months was lowest in the HIC $(46.6 \pm 31.1)$, while continued breastfeeding for 24 months was lowest in MIC (22.5 \pm 15.5$)$ (Table 2). 


\begin{tabular}{|l|l|l|l|l|}
\hline & LIC (6) & MIC (10) & HIC (6) & Total \\
\hline $\begin{array}{l}\text { Timely Initiation of breastfeeding (TFS) } \\
\text { Mean } \pm \text { SDs }\end{array}$ & 63.6 & $41.7 \pm 24.2$ & $60.25 \pm 27.8$ & $48.5 \pm 24.25$ \\
\hline $\begin{array}{l}\text { Exclusive Breastfeeding } \\
\text { Mean } \pm \text { SDs }\end{array}$ & $25 \pm 23.79$ & $35.6 \pm 16.63$ & $32.02 \pm 20.37$ & $34.03 \pm 18.88$ \\
\hline Continued Breastfeeding for 12 months Mean \pm SDs & $69.94 \pm 20.45$ & $53.11 \pm 13$ & $46.6 \pm 31.1$ & $62.5 \pm 20.05$ \\
\hline $\begin{array}{l}\text { Continued Breastfeeding for 24 months } \\
\text { Mean } \pm \text { SDs }\end{array}$ & $38.7 \pm 23.3$ & $22.5 \pm 15.5$ & $28.5 \pm 18.1$ & $28.9 \pm 18.09$ \\
\hline
\end{tabular}

Table 2: Comparison of the early infant feeding data and indices of nutritional status in countries of EMRO by level of income.

Stunting for the under-fives was highest in the LIC $(39.58 \pm 6.37)$ and lowest in the HIC $(7.6 \pm 3.81)$. Wasting for under-fives was highest in the LIC $(17.96 \pm 8.99)$ and low in the MIC and HIC $(5.51 \pm 3.21$, $6.92 \pm 4.25$ respectively). Overweight in the under-fives was highest in the MIC $(12.72 \pm 5.25)$ compared to the LIC $(4.62 \pm 2.7)$ and HIC $(6.38 \pm 5.002)$. Obesity in the under-fives was prevalent in both the MIC $(4.75 \pm 3.1)$ and the HIC $(5.45 \pm 6.03)$ with no statistical significant difference between the groups under study (Table 3 ).

\begin{tabular}{|l|l|l|l|l|}
\hline Categories of countries & LIC & MIC & HIC & Total \\
\hline $\begin{array}{l}\text { U5 Stunting } \\
\text { Mean } \pm \text { SDS }\end{array}$ & $39.58 \pm 6.37$ & $17.04 \pm 11.5$ & $7.6 \pm 3.81$ & $20.16 \pm 14.69$ \\
\hline $\begin{array}{l}\text { U5 Wasting } \\
\text { Mean } \pm \text { SDS }\end{array}$ & $17.96 \pm 8.99$ & $5.51 \pm 3.21$ & $6.92 \pm 4.25$ & $8.8 \pm 7.3$ \\
\hline $\begin{array}{l}\text { U5 Overweight } \\
\text { Mean } \pm \text { SDS }\end{array}$ & $4.62 \pm 2.7$ & $12.72 \pm 5.25$ & $6.38 \pm 5.002$ & $9.5 \pm 5.87$ \\
\hline $\begin{array}{l}\text { U5 Obesity } \\
\text { Mean } \pm \text { SDS }\end{array}$ & NA & $4.75 \pm 3.1$ & $5.45 \pm 6.03$ & $4.8 \pm 3.94$ \\
\hline $\begin{array}{l}\text { Adult overweight } \\
\text { Mean } \pm \text { SDS }\end{array}$ & $28.68 \pm 11.82$ & $58.2 \pm 12.63$ & $72.7 \pm 3.92$ & $55.4 \pm 19.13$ \\
\hline $\begin{array}{l}\text { Adult Obesity } \\
\text { Mean } \pm \text { SDS }\end{array}$ & $8.36 \pm 5.58$ & $25.4 \pm 7.5$ & $36.65 \pm 4.019$ & $24.6 \pm 11.88$ \\
\hline \begin{tabular}{l} 
LIC: low income countries, MIC: middle income countries, HIC: high income countries \\
\hline
\end{tabular}
\end{tabular}

Table 3: Comparison of the of nutritional indices in children under-five of age and obesity and overweight prevalence rates of adults in the countries of the Eastern Mediterranean Region by level of income.

Timely first suckle (TFS) (initiation of breastfeeding within the first hour of birth) showed a moderately high negative correlation with overweight and obesity rates of children under five years of age ( $\mathrm{r} 0.51$ and $\mathrm{r} 0.51$ respectively at $\mathrm{P}<0.05)$. Also, TFS was negatively correlated to obesity and overweight among adults ( $\mathrm{r}-0.3$ and $\mathrm{r}-0.03$ respectively at $\mathrm{P}<0.05$ ) (Table 4).

Adolescent overweight and obesity showed moderately high negative correlations with $\mathrm{EBF}(\mathrm{r}-0.64$ and $\mathrm{r}-0.54$ at $\mathrm{P}<0.01)$ and continued breastfeeding for 12 months ( $\mathrm{r}-0.56$ and $\mathrm{r}-0.21$ respectively at $\mathrm{P}<0.05)$ and 24 months $(\mathrm{r}-0.33$ and $\mathrm{r}-0.49$ respectively at $\mathrm{P}<0.05)$. Unfortunately, we could only do these correlations for a limited number of countries for the data for youth's overweight and obesity was not available in the other countries.
Data from all the 22 countries for the adults showed significant negative correlations for overweight and obesity with breastfeeding continuity at 12 months $(\mathrm{r}-0.54$ and $\mathrm{r}-0.56)$ respectively at $\mathrm{P}<0.01$ and at 24 months $(\mathrm{r}-0.45$ and $\mathrm{r}-0.49)$ respectively at $\mathrm{P}<0.01$, but not with early EBF (Table 3 ).

Data from the retrospective in-depth study in one country are presented in Table 5 and shows that there was significant difference in weight and weight centiles between children under five of age who were breastfed and children who were artificially fed that was highly significant $\mathrm{P}<0.001$. There were no differences in height, head circumference or mid arm circumference. All children were not obese and had appropriate weight for length. 
Citation: Abul-Fadl A, El Bakry S (2018) Obesity and Optimal Breastfeeding Practices in Developing Countries: A Double Staged Study. Vitam Miner 7: 177.

Page 5 of 7

\begin{tabular}{|c|c|c|c|c|}
\hline Nutritional Indices & $\begin{array}{l}\text { Timely first suckle (within } \\
\text { the First hour) (17) }\end{array}$ & $\begin{array}{l}\text { Exclusive breastfeeding ( } 0-5 \\
\text { mo) ( } 22 \text { country) }\end{array}$ & $\begin{array}{l}\text { Continued } \\
\text { breastfeeding for } 12 \\
\text { months ( } 21 \text { country) }\end{array}$ & $\begin{array}{l}\text { Continued breastfeeding for } 24 \\
\text { months ( } 17 \text { country) }\end{array}$ \\
\hline \multicolumn{5}{|l|}{ Children under five } \\
\hline -Stunting (20) & r 0.09 & r 0.05 & $r+0.69^{* *}$ & $r+0.908^{* *}$ \\
\hline -Wasting (20) & r 0.22 & r 0.13 & $r+0.67^{* *}$ & $r+0.87^{* *}$ \\
\hline -Overweight (20) & $r-0.51^{*}$ & r 0.11 & $r-0.05$ & $r-0.36$ \\
\hline -Obesity (14) & $\mathrm{r}-0.51^{*}$ & r 0.22 & $r-0.475^{*}$ & $\mathrm{r}-0.33$ \\
\hline \multicolumn{5}{|l|}{ Youth (13-18 years) } \\
\hline -Overweight (10) & r 0.06 & $\mathrm{r}-0.64^{*}$ & $r-0.563$ & $r-0.33$ \\
\hline -Obesity (10) & r 0.07 & $r-0.54^{*}$ & $\mathrm{r}-0.212$ & $r-0.49$ \\
\hline \multicolumn{5}{|l|}{ Adult (+18 years) } \\
\hline -Overweight (22) & $r-0.33$ & $r-0.07$ & $r-0.54^{* *}$ & $\mathrm{r}-0.45^{*}$ \\
\hline -Obesity (22) & $\mathrm{r}-0.37$ & $r-0.09$ & $r-0.56^{* *}$ & $r-0.49^{*}$ \\
\hline
\end{tabular}

Table 4: Correlative studies between breastfeeding indices and nutritional indices for children under five of age, youth and adults.

\begin{tabular}{|c|c|c|c|}
\hline & Breastfed fed $(60)$ & Artificially fed (60) & \\
\hline & Mean age \pm SDs & Mean \pm SDs & p-value \\
\hline Child age at assessment & $52.1 \pm 8.7$ & $49.1 \pm 9.7$ & $p>0.05$ \\
\hline Mother age at assessment & $25.9 \pm 2.02$ & $25.7 \pm 2.57$ & $p>0.05$ \\
\hline Duration of exclusive breastfeeding(months) & $4.28 \pm 0.85$ & 0 & - \\
\hline Age of cessation of breastfeeding(months) & $15.83 \pm 3.19$ & 0 & - \\
\hline Weight (Kg) & $16.075 \pm 1.58335$ & $16.675 \pm 1.67$ & $0.046^{*}$ \\
\hline Weight Centile & $38.17 \pm 14.84$ & $51.8 \pm 21.84$ & $<0.001^{* \star *}$ \\
\hline Length/ height $(\mathrm{cm})$ & $100.0 \pm 85.46$ & $101.13 \pm 5.79$ & 0.309 \\
\hline Length Centile & $53.6 \pm 18.88$ & $51.17 \pm 18.92$ & 0.21 \\
\hline Head Circumference (cm) & $49.85 \pm 0.97$ & $49.65 \pm 0.99$ & 0.266 \\
\hline Mid arm circumference $(\mathrm{cm})$ & $14.22 \pm 0.31$ & $14.125 \pm 0.33$ & 0.118 \\
\hline
\end{tabular}

Table 5: Comparison of breastfeeding practices and nutritional assessment findings in the groups under study (breastfed versus non-breastfed fed children under-five years of age).

\section{Discussion}

Until recently breastfeeding rates for continuity were measured by continued breastfeeding for 12 months only. In the countries of the Eastern Mediterranean region (EMR) breastfeeding continuity rates are low especially rates of continuity for 24 months. We found that one half of the EMR countries have no data reported for these rates, and monitoring systems do not include them in their nutritional surveillance systems.

In this study we found that countries with the highest problem of overweight were those in the gulf area i.e., the GCC countries with Qatar leading at $78.1 \%$ followed by Kuwait at $75.4 \%$, UAE $74 \%$ and Bahrain $71 \%$. Hence one in every 3 to 4 subjects of the population is overweight. The top leading countries with the problem of obesity were 
again Qatar (42\%), Kuwait (39.7\%), UAE (37.2\%) and Bahrain (35\%). However, we found no differences in the breastfeeding indices between countries of low, middle and high income (LIC, MIC, HIC respectively). Timely first suckle was delayed mostly in LIC while continued breastfeeding rates were lowest in the HIC and MIC. Many studies in the Eastern Mediterranean region [11-13] have demonstrated that sedentary life, lack of physical exercise and poor dietary habits were reported as the main underlying causes for these high profiles of overweight and obesity especially.

However, in this study there were significant relationships between early feeding practices and the increased risk of obesity as there was significant relationship between timely first suckle rates for 17 countries of EMR and the overweight and obesity rates for the underfives of age ( $\mathrm{r}-0.51$ and $\mathrm{r}-0.52$ respectively) and adults ( $\mathrm{r}-0.38$ and $\mathrm{r}-0.33$ respectively). This could due to the effect of timely first suckle on the continuity and exclusivity of breastfeeding, increasing the bonding and thereby reinforcing responsive feeding. This was substantiated by many other workers [14-17] who reported that early feeding practices play an important role in the development of overweight and obesity later on in life.

There were no significant relationships with EBF and the nutritional indices. Adolescent overweight and obesity showed moderately high negative correlations with EBF ( $\mathrm{r}-0.64$ and $\mathrm{r}-0.54)$ and continued breastfeeding for 24 months ( $\mathrm{r}-0.77$ and $\mathrm{r}-0.64$ respectively). Unfortunately, we could only do these correlations for data about youth from 10 and 9 countries for overweight and obesity respectively, due to lack of reporting. However, data from all the 22 countries were available for the adults and there were significant negative correlations for overweight and obesity with breastfeeding continuity for 12 months (r-0.49 and r- 0.49 respectively) and for 24 months ( $\mathrm{r}-0.52$ and $\mathrm{r}-0.52$ respectively). This indicates that continuity plays a protective role against obesity. It would be interesting to link it to puberty and that hormonal configuration at puberty that could be influenced by early feeding practices and hence sexuality and reproductive health [16]. A study in Berkely [17] has shown that young girls who were exposed to formula feeding in early infancy had increased body mass index and delayed puberty. It seems that endocrine factors that influence puberty may have their origins from early infancy [18]. The role of microbiota that develop early in infancy under the effect of the microbiome which is influenced by breastfeeding [19] may influence predisposition to obesity [20] and pubertal development [21].

In the in-depth retrospective study of the 120 preschool children we found that the artificially fed children tended to be heavier than the breastfed children and parents complained more of feeding problems in these children. None of the children were obese or underweight and weight for height was appropriate for all children, but the artificially fed tended to be on the higher centiles and had a wide variance. This validates our regional data but is limited by sample size. Early feeding practices contribute to the increased risk of obesity in many ways. The first would be the deprivation from colostrum as the sensitizer of the immune system of gastrointestinal tract and the increasing role of microbiota in directing the immune system of the body towards enhancing and protecting the optimal development of the immune system and directs the life style and programming the feeding habits of the child from early on in life. Early exposure to high protein content found in the formula predispose to obesity $[4,5]$.

A systematic review identified significant associations between childhood overweight and maternal pre-pregnancy overweight, smoking during pregnancy, high infant birth-weight and rapid weight gain [4]. Estimates varied, but between $25 \%$ and $33 \%$ of infants gained weight more rapidly than is desirable during the first 6 months of life and this is a strong risk factor for the development of childhood obesity $[4,7,8,22]$. A meta-analysis found breastfeeding decreased the odds of childhood overweight by $15 \%$ [23]. However, single studies have also found significant associations between early introduction of solid foods [24], shorter breastfeeding duration [25], higher energy intake [8], shorter sleep duration [26], high maternal control over feeding, sedentary lifestyle and the risk of childhood obesity [27]. Responsive feeding was reported to be protective against childhood obesity [5].

Trends in obesity are increasing not only in our region, but all around the world. Obesity rates in the world's children and adolescents increased from less than $1 \%$ (equivalent to five million girls and six million boys) in 1975 to nearly $6 \%$ in girls (50 million) and nearly $8 \%$ in boys ( 74 million) in 2016. Combined, the number of obese five to 19-year old rose more than tenfold globally, from 11 million in 1975 to 124 million in 2016. An additional 213 million were overweight in 2016 but fell below the threshold for obesity [27]. However, its relation to the duration of breastfeeding has been poorly understood [5]. In this case we need to distinguish between extended breastfeeding into the second year and beyond and just breastfeeding towards 6 or even 12 months.

The duration of breastfeeding that extends well into the second year may be a part of human development and genetic predisposition. The link between shortened duration of breastfeeding and predisposition to obesity and chronic diseases is explained by increased exposures to oxidative stress and inflammation which are associated with accelerated telomere (TL) shortening in adults. Breastfeeding has a protective effect against inflammation and this may explain the findings of some workers [28] of an association between EBF at 4-6 weeks of age and longer TL in the preschool years. This may be even more apparent if the study was extended into the second year.

We conclude that the problem of overweight and obesity which is escalating to reach alarming levels worldwide $[29,30]$ and particularly in the EMR where it is of major public health concern to the region, has strong links early feeding practices and in particular to the duration of breastfeeding [31]. Other early feeding practices especially delayed breastfeeding initiation; early introduction of high protein feeds, poor maternal health and shortened duration of breastfeeding, play significant roles in the development of obesity and should be used as key strategies for developing interventions for prevention and control of this pandemic that is invading our region and the world. Socioeconomic status does not influence obesity as it is prevalent among low, middle and high-income countries [11,12]. Suboptimal early infant practices are widely prevalent in all income subgroups and requires educational campaigns to change beliefs and behavior.

We suggest that strategies for raising awareness, through education, modeling behavior, changing health facility practices and communitybased interventions [4] can be effective in improving breastfeeding practices and thereby decreasing the pandemic of obesity in the EMR countries. Governments in the region should be guided by the "proposed policies for preventing obesity and diabetes in the Eastern Mediterranean Region" [32]. The latter outlines the guidelines for interventions to promote, protect and support breastfeeding through Baby Friendly health systems and effective community-based strategies, fully implement the Code and empower women in workplaces to exclusively breastfeed through mandatory paid leaves [31]. 


\section{References}

1. World Health Organization (2003) United Nations Children's Fund. Global Strategy for Infant and Young Child Feeding. Geneva, Switzerland: WHO

2. Black RE, Victora CG, Walker SP, Bhutta ZA, Christian P, et al. (2013) Maternal and child undernutrition and overweight in low-income and middle-income countries. Lancet 382: 427-451.

3. Horta BL, De Mola C, Victora CG (2015) Long-term consequences of breastfeeding on cholesterol, obesity, systolic blood pressure and type 2 diabetes: a systematic review and meta-analysis. Acta Pædiatrica 104: 30-37.

4. Weng SF, Redsell SA, Swift JA, Yang M, Glazebrook CP (2012) Systematic review and meta-analyses of risk factors for childhood overweight identifiable during infancy. Archives of Disease in Childhood 97: 1019-1026.

5. DiSantis KI, Hodges EA, Johnson SL, Fisher JO (2011) The role of responsive feeding in overweight during infancy and toddlerhood: a systematic review. Int J Obe 35: 480-492.

6. Musaiger AO, Al-Mannai M, Al-Haifi AR, Nabag F, Elati J, et al. (2016) Prevalence of overweight and obesity among adolescents in eight Arab countries: comparison between two international standards (ARABEAT-2). Nutr Hosp 33: 1062-1065.

7. Monteiro P, Victora CG (2005) Rapid growth in infancy and childhood and obesity in later life - a systematic review. Obesity Reviews, pp: 143-154.

8. Ong K, Loos R (2006) Rapid infancy weight gain and subsequent obesity: systematic reviews and hopeful suggestions. Acta Paediatrica 95: 904-908.

9. Oot L, Sethuraman K, Ross J, Sommerfelt AE (2017) The effect of suboptimal breastfeeding on preschool overweight/obesity: A model in PROFILES for country-level advocacy.

10. Al-Hreashy FA, Tamim HM, Al-Baz N, Al-Kharji NH, Al-Amer A, et al. (2008) Patterns of breastfeeding practice during the first 6 months of life in Saudi Arabia. Saudi Med J 29: 427-431.

11. Papandreou C, Mourad TA, Jildeh C, Abdeen Z, Philalithis A, et al. (2008) Obesity in Mediterranean region (1997-2007): A systematic review. Obe Rev 9: 389-399.

12. Musaiger O (2004) Overweight and obesity in the Eastern Mediterranean Region: can we control it? Eastern Mediterranean Health Journal 10: 789-793.

13. Al-Hazzaa HM (2004) Prevalence of physical inactivity in Saudi Arabia: a brief review. Eastern Mediterranean Health Journal 10: 663-670.

14. Victora CG, Bahl R, Barros AJ, França GV, Horton S, et al. (2016) Breastfeeding in the 21st century: Epidemiology, mechanisms, and lifelong effect. Lancet 387: 457-490.

15. Gardner D, Hosking J, Metcalf BS, Jeffery AN, Voss LD, et al. (2009) Contribution of early weight gain to childhood overweight and metabolic health: a longitudinal study (EarlyBird 36). Pediatrics 123: 67-73.

16. Kale A, Deardorff J, Lahiff M, Laurent C, Greenspan LC, et al. (2015) Breastfeeding versus Formula-Feeding \& Girls' Pubertal Development. Matern Child Health J 19: 519-527.

17. Ekelund U, Ong K, Linne Y, Neovius M, Brage S, et al. (2006) Upward weight percentile crossing in infancy and early childhood independently predicts fat mass in young adults: the Stockholm Weight Development Study (SWEDES). The American J Clin Nut 83: 324-330.

18. Mann DR, Johnson AO, Gimpel T, Castracane VD (2003) Changes in circulating leptin, leptin receptor, and gonadal hormones from infancy until advanced age in humans. J Clin Endocrinol Metab 88: 3339-3345.

19. Penders J, Thijs C, Vink C, Stelma FF, Snijders B, et al. (2006) Factors influencing the composition of the intestinal microbiota in early infancy. Pediatrics 118: 511-521.

20. Rogier EW, Frantz AL, Bruno M, Wedlund L, Cohen DA, et al. (2014) CS Lessons from mother: Long-term impact of antibodies in breast milk on the gut microbiota and intestinal immune system of breastfed offspring. Gut Microbes 5: 663-668.

21. Neufeld KM, Luczynski P, Dinan TG, Cryan JF (2016) Reframing the Teenage Wasteland: Adolescent Microbiota-Gut-Brain Axis. The Canadian J Psychiatry 61: 214-221.

22. Hui L, Schooling CM, Leung SS, Mak KH, Ho LM, et al. (2008) Birth weight, infant growth, and childhood body mass index: Hong Kong's children of 1997 birth cohort. Archives of Pediatrics \& Adolescent Medicine 162: 212-218.

23. Weng S, Redsell SA, Nathan D, Swift JA, Yang M, et al. (2013) Developing an algorithm to estimate overweight risk in childhood from predictors during infancy. Pediatrics 132: 414-421.

24. Jonsdottir OH, Thorsdottir I, Hibberd PL, Fewtrell MS, Wells JC, et al. (2012) Timing of the introduction of complementary foods in infancy: a randomized controlled trial. Pediatrics 130: 1038-1045.

25. Weyermann M, Rothenbacher D, Brenner H (2006) Duration of breastfeeding and risk of overweight in childhood: a prospective birth cohort study from Germany. Int J Obesity 30: 1281-1287.

26. Taveras EM, Rifas-Shiman SL, Oken E, Gunderson EP, Gillman MW (2008) Short sleep duration in infancy and risk of childhood overweight. Archives of Pediatrics \& Adolescent Medicine 162: 305-311.

27. Brophy S, Cooksey R, Gravenor MB, Mistry R, Thomas N, et al. (2009) Risk factors for childhood obesity at age 5: analysis of the millennium cohort study. BMC Public Health 9: 467.

28. Wojcicki JM, Heyman MB, Elwan D, Lin J, Blackburn E, et al. (2016) Early exclusive breastfeeding is associated with longer telomeres in Latino preschool children. Am J Clin Nutr 104: 397-405.

29. Jones G, Steketee RW, Black RE, Bhutta ZA, Morris SS (2003) How many child deaths can we prevent this year? Lancet 362: 65-71.

30. Abarca-Gomez L, Abdeen ZA, Hamid ZA, Abu-Rmeileh NM, AcostaCazares B, et al. (2017) Worldwide trends in body-mass index, underweight, overweight, and obesity from 1975 to 2016: a pooled analysis of 2416 population-based measurement studies in 128.9 million children, adolescents, and adults. Lancet 390: 2627-2642.

31. Harder T, Bergmann R, Kallischnigg G, Plagemann A (2005) Duration of breastfeeding and risk of overweight: a meta-analysis. Am J Epidemiol 162: 397-403.

32. Alwan A, McColl K, Al-Jawaldeh A (2017) WHO-EMRO. Proposed policy priorities for preventing obesity and diabetes in the Eastern Mediterranean Region. EMRO technical publication series. 